\title{
BEHAVIORAL MODEL OF BUSINESS CHANGE MANAGEMENT IN RELATION TO BUILDING COMPETITIVENESS IN MARKET ECONOMY CONDITIONS
}

\author{
David VRTANA (1*), Zuzana ROSNEROVA (D), Anna KRIZANOVA® \\ Department of Economics, Faculty of Operation and Economics of Transport and Communications, \\ University of Zilina, Univerzitna 1, 01026 Zilina, Slovakia
}

Received 17 July 2021; accepted 20 October 2021

\begin{abstract}
In the current market environment, the actual dynamics of the application of internal corporate factors is differentiated. The company thus tries to influence customers' shopping behavior as effectively as possible. Therefore, it is important for the company to be able to adapt to these changes as effectively as possible. The purpose of the article is to analyze the factors influencing consumer behavior in the market conditions of the Slovak Republic. We described the current situation by a survey, which we conducted in 2020-2021. Among the selected categorical variables, we verified the dependence in two hypotheses by the statistical method of Pearson's Chi-Square test. Using the method, we pointed out the factors that influence consumer behavior and can be important for change management. We compared the results of the survey with the results of similar surveys conducted abroad. Accepting the results of the survey, we proposed a general model of change management in the discussion part of the article. The model is thus a practical implication for companies with a differentiated subject of business. It also takes into account the behavioral characteristics that the company should adapt to in the current situation in order to achieve its strategic goals.
\end{abstract}

Keywords: consumer, business change management, consumer policy, competitiveness, behavioralism, emotional marketing, trends.

JEL Classification: M30, M31, M37.

\section{Introduction}

The evolution of consumer behavior has changed significantly since the beginning of the development of the neoclassical economy. In the current market environment, there is a socio-psychological phenomenon of cognitive dissonance. Through research, Clore (2011) has shown that when people act in a way that is not in line with their beliefs, tension is created and emotions are created. These can then motivate customers to make emotional and intuitive decision-making processes (Clore, 2011). The cognitive dissonance factor is currently crucial, not only for the external business environment, but also for internal ones. In an internal business environment, a business must make a number of changes. These are necessary to adapt to innovative trends in purchasing behavior and customer decisions. Within the trends, the company must take into account various factors such as behavioral elements, the importance of the generation chain, the form of shopping behavior, lifestyle and the like. All of these factors should be an important part of change management. In the process of change management, there should be an integration of cognitive and affective factors, which also include irrational customer decision-making processes. In his research, Clore (2011) emphasized that from the company's point of view, it is necessary to perceive and evaluate the effect of emotions by applying communication tools. Current trends in shopping behavior and decision making are part of the evolutionary development of consumer behavior in a market environment.

In this regard, Baumeister et al. (2012) emphasize that each type of behavior is related to emotions because it is motivated by the expected effect. In the sense of the authors, mental stimulations are involved in order to predict probabilistic results. Later, when maximizing decisions, emotional decision-making processes manifest themselves, which activate irrational customer behavior in a market environment. The authors of Clore and Huntsinger (2007) have a different view of this issue, according to

*Corresponding author. E-mail: david.vrtana@fpedas.uniza.sk 
which, despite the unconscious, automatic, emotional and heuristic nature of general thinking, rational and defensible conclusions are ultimately drawn. In connection with shopping behavior, the authors commented that rational decision-making processes occur only after the influence of emotional decision-making processes.

Based on the authors' statements, we can say that rational and emotional decision-making processes are involved in consumer shopping behavior, but in a differentiated sense, as assumed by traditional economic theory. Emotional action therefore has a major impact on consumer shopping behavior and decision-making.

The importance of our study is to analyze the factors influencing current trends in purchasing behavior and customer decision-making in a market economy. Through research, we have identified the importance of irrational purchasing behavior in conjunction with the factors that influence it.

The novelty of our research is the pointing out of behavioral elements in the shopping behavior and decisions of customers and their comparison with foreign research. The added value is also the creation of a model based on the results of our research. As a similar survey was not carried out in the market economy of the Slovak Republic, its added value is for companies whose goal is to create such a communication campaign that respects elements of irrationality in customers' shopping behavior.

The main goal of the research is to analyze the current state of consumer behavior and create a general model of change management, including a subset of change marketing. It also contains trends in irrational shopping behavior. We will fulfill the main goal of our study with the following sub-goals:

- analysis of the theoretical basis of purchasing behavior and decision-making in terms of penetration and differences,

- analysis of the theoretical basis of change management in relation to customer purchasing behavior,

- to present the results of a survey carried out in the conditions of the market economy of the Slovak Republic,

- in the discussion part, compare the results of the survey with the results of other studies, create a model of change management and verify its validity.

We conducted a survey, the aim of which was not only to analyze consumer shopping behavior and identify factors of irrationality, but also to determine a possible correlation between selected categorical variables.

To fulfill the main goal of our study, we defined two hypotheses in which we looked for the relationship between consumer behavior and gross monthly income of consumers

Hypothesis 1:

H0: There is no dependence between the categorical features of gross monthly income and the scope of advertising with an emotional appeal to customers' shopping behavior.
H1: There is a dependence between the categorical features of gross monthly income and the scope of advertising with an emotional appeal to customers' shopping behavior.

Hypothesis 2:

H0: There is no relationship between the categorical features of gross monthly income and decision-making between two sweet products.

H1: There is a relationship between the categorical features of gross monthly income and decision-making between two sweet products.

Finding the dependence between the examined categorical variables is crucial in order to be able to define the significance of irrational purchasing behavior in our proposed general model of change management.

In the study we used the following methods: comparison of theoretical background, analysis, synthesis, deduction, descriptive statistics, induction, excerption, Pearson's Chi Square test.

\section{Analysis of the theoretical basis of purchasing behavior and decision-making in terms of penetration and differences}

We analyze concepts of purchasing behavior and decisionmaking in this chapter in terms of penetration and differences.

\subsection{Shopping behavior}

Chen and Yang (2020) argue that the process of buying behavior is focused on overt and observable acts in the form of buying and consuming. The authors further extend their claim to knowledge in the form of mental and social processes that take place before purchase (awareness of needs, attitude formation, evaluation of alternatives, product selection and place of purchase), during purchase (shopping behavior), after purchase (utility evaluation, comparison expected reality and consumption process). The authors have divided the procedural view of purchasing behavior into three categories, which include other procedural steps directly related to purchasing activity. This view can be identified with a procedural statement according to Beall and Tracy (2017), who, however, defined it as a purchasing decision.

According to Chen et al. (2016) Purchasing behavior is not only related to a specific purchase of a product or service. It is important to perceive it as a vast complex of interconnected and effecting components that must be seen in the context of other components of human behavior. The authors highlighted the complexity and coherence as key factors in the process of purchasing behavior.

Shopping behavior can have two results, a positive one and a negative one. These results of the behavioral process are dealt with in Berne-Manero and Marzo-Navarro (2020), who defined it as a model. The model generally defines how events can lead to the above results. The model is shown in Figure 1. 


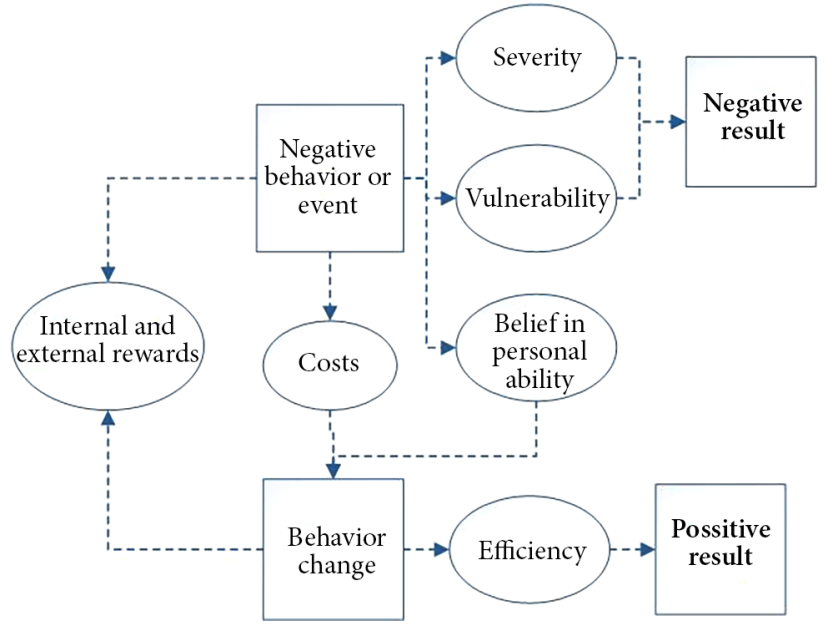

Figure 1. Model of shopping behavior (source: Berne-Manero \& Marzo-Navarro, 2020)

We perceive the model as incomplete, especially when assessing the severity and vulnerability of negative behavior or events to the customer. The model shows how negative behavior can affect the overall negative attitude that the customer can create in relation to the purchase. In this regard, it is necessary to supplement the authors with individual phases of a negative result. If the severity of the negative behavior or event is high or the severity is low, the negative outcome can be differentiated according to the degree of severity. Negative behavior or an event can affect our overall behavior and, with some effectiveness, can ultimately yield a positive result. For example, in the case of strengthening the emotion of fear in connection with the purchase of a certain product.

Plessis (2011) effectively linked heuristics-related shopping behavior in his research. At present, customers use mental heuristics in most decisions, especially when comparing and evaluating brands and products. We agree with the author's statement, because customers are currently exposed to a large number of brands. The perceptions and feelings of customers are interpreted through neural networks, which evoke a memory with a specific product or brand. In the end, the customer prefers a product that evokes a positive emotion in him.

\subsection{Purchasing decision-making}

The authors Jermsittiparsert et al. (2019) pointed out the difference between purchasing behavior and decisionmaking. We understand shopping behavior as a process of physical and mental activity that customers spend on evaluating, acquiring and using products and services.

They likened purchasing decision-making to a process of steps consisting of three basic parts. These sections include problem identification, finding and evaluating purchasing processes, and evaluating post-purchase decisions. Although the authors pointed out the differences in the concepts of shopping behavior and decision-making, their views are conceived in a general level. In consumer behavior, the authors talk about the decision-making process. In this sense, we do not agree with the authors' statements, as the authors tried to point out the differences in concepts and defined purchasing behavior as a decision-making process. Within the difference, the authors pointed out the connection of terms.

Adekiya (2016) argues that purchasing decision-making is a process in which a problem (need) is identified and information is sought to help customers make a rational decision. The author confirms the general view of purchasing decisions and lacks detailed process steps leading to the customer's final decision to purchase a product or service.

Another view of purchasing decisions is provided by Chen et al. (2016). Through research on purchasing decisions, they found that when making a final decision to purchase a product or service, customers compare certain factors (e.g. fashion trends, price, reliability, quality, etc.). We agree with the authors' statement and we can include their statement in the process step of evaluating alternatives within the purchasing decision model. It is also important to compare the factors that determine the final purchase decision. Customers compare individual alternatives through various criteria (e.g. price, reliability, quality, etc.). Subsequently, according to the general model of expectation - value, they choose the most advantageous alternative. The disadvantage is the genesis of their result in the plane of one process step within the final model. The authors did not provide a general view of the purchasing decision model, claiming what influences the customer's final decision.

The generalization of the assumptions about decisionmaking is the statement of the authors Socha and Beck (2015). They argue that there are a number of theories and models that are divided into decision-making processes and decision-making strategies. Final decision making is part of the social sciences in the field of cognitive psychology. The final decision is not only a choice, but also a thoughtful action that involves assessing alternatives in terms of advantages and disadvantages.

\subsection{Penetration of shopping behaviour and decision-making}

On the basis of generalized statements about the mentioned concepts, it is necessary to point out their penetration. The authors in the previous subchapters indirectly commented on the intersections of the terms in question. The relationship between purchasing decision-making and behavior was also pointed out by Victor et al. (2018), according to which the company must have a good knowledge of purchasing behavior, including the factors that subsequently determine the final decision. Only then can the company properly satisfy the needs of the customer. In this relationship, the author expresses a significant intersection between the concepts we have examined.

However, some authors pointed in their statements directly to the connection between the concepts of purchasing behavior and decision-making. These authors include 
Socha and Beck (2015). They argue that when examining purchasing behavior, we should focus on those decisionmaking processes and strategies that affect the customer's position in the market environment.

Based on the defined intersections, we can express the relationship between purchasing behavior and decisionmaking through Figure 2.

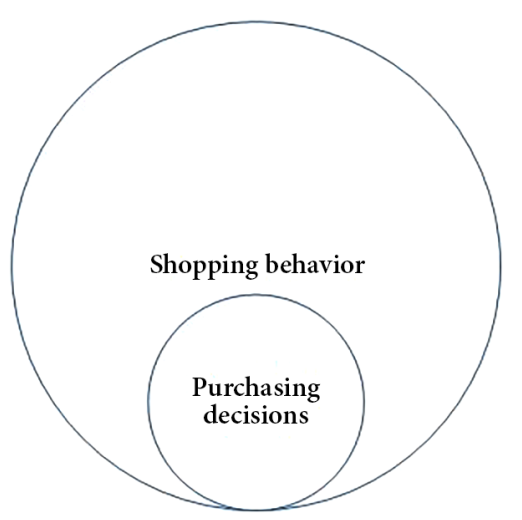

Figure 2. Penetration of shopping behavior and decision-making

\section{Analysis of the theoretical basis of change management in relation to customer purchasing behavior}

The current market environment is characterized by rapid development with ever-changing conditions that companies are forced to monitor in order to stay on the market. Three forces, globally abbreviated as " 3 C" (Littlechild, 2019), have a major impact on business activity and mutual integration:

C - customers;

C - competition;

$\mathrm{C}$ - change.

Today, customers are considered a key element to which businesses submit and are forced to monitor changes in customer requirements. In the current context, competition is not only understood from a regional point of view, given that it has spread on a global scale (Deng et al., 2019). Business management, in turn, focuses on managing change that is at the top of the customer's scale of interests and must continuously make decisions that are directly linked to changes in the ever-changing market environment (Vuorinen \& Martinsuo, 2019). The process management of the company reflects on the constantly emerging changes. Under the term process we understand a certain organized group of activities that follow each other and bring a certain effect or result. Each process requires certain inputs, which must be defined in advance and relate to the specification of the need for people, material, goods, documentation, etc. and on the basis of the inputs thus defined, it is subsequently able to bring a certain output to the enterprise (Sjodin, 2019). The goal of the process can be understood as a certain procedure that will be applied in the company to achieve the desired output. However, an important condition is that the specified procedure works in a way that yields only one output. Change management is a concept that aims to guide, prepare and support individuals in order to successfully embrace change, with the primary goal of achieving success in a specific area where the desired results can be achieved. Change management can be linked not only to business process management, but can also be linked to marketing. Each consumer decides on the purchase himself, based on their needs and available alternatives and information. Purchasing decisions are largely influenced by various qualitative and quantitative factors, where each consumer individually evaluates the available product alternatives. The goal of each business is to intensify its marketing reach and revenue by maximizing the satisfaction of its customers' needs (Gubruz \& Macabangin, 2019). The basic aspect in the field of marketing is to determine the shopping behavior of customers through the elements on the basis of which it is possible to directly influence the customer. Consumer behavior can be defined as the attitude that the consumer manifests when searching for, buying and consuming or using a particular product (Gubruz \& Macabangin, 2019). Srivastava and Wagh (2017) found that in the field of consumer purchasing, 5 factors are decisive and responsible: influencers, awareness, reliability, promotion and business image. It is in this case that we see the connection of change management with the marketing area of the company, as through the management of business processes it is possible to influence marketing activities and indirectly affect consumer behavior. In the issue of change management, it is possible to solve the process itself, which must consist of individual steps, in which their mutual continuity is very important. We can highlight the principle of the CMMI model, which is referred to as the stepwise maturity model. Capability Maturity Model Integration (referred to as CMMI) is a process and behavioral model that helps companies direct and improve processes and stimulates effective behavior that reduces business risks arising from the development of new products or services (Pour \& Jafari, 2019). The principle of the CMMI model consists of 5 levels of process maturity, on the basis of which the company can identify a specific level of the process and also can identify critical sections and help select an appropriate strategy to improve the process to a higher level of maturity. The direction of individual activities is important especially in the question of fulfilling the required goal, which the company tries to achieve with the help of a controlled apparatus. Figure 3 shows the sequence of the CMMI model and the transition of individual growth levels.

The interaction between the CMMI model and consumer shopping behavior can be linked as follows. The first step of the CMMI model is determined as an initial level within which business processes are not significantly organized, they are unrepeatable because the processes are not sufficiently specified and documented (Wei et al., 2019). This step is characterized by a considerable impossibility in ensuring the control of business processes. We 


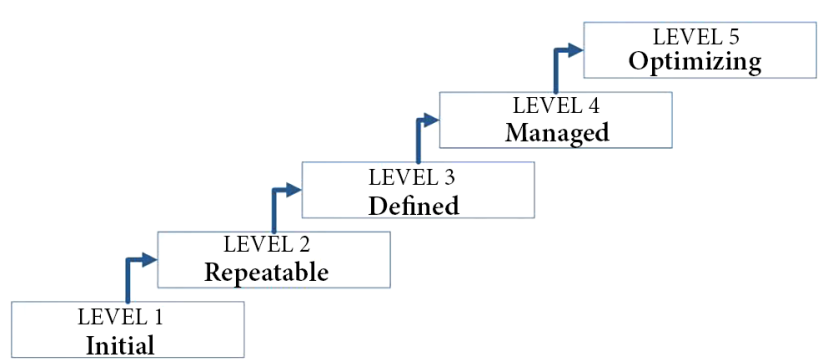

Figure 3. Levels of CMMI model (source: Pour \& Jafari, 2019)

can identify the bridging of this step into the marketing area in such a way that the company does not make an effort to map the interest of consumers in its products and at the same time does not document the information that would serve as a basis for further activities of the company in the future. The second step of this model is presented as a repeatable level, in which elements and techniques of project management are already beginning to appear and the success of the process is perceived as repeatable, based on a more advanced perception of processes compared to the first level (Ramirez-Mora et al., 2020). Business processes are predefined and subsequently documented. In the case of connection with marketing, this level of process management can be considered more advanced, because the elements are planned, which will be identified in the field of purchasing behavior and also all the information found is documented. The company creates projects that are planned, subsequently implemented, measured and finally controlled. The third level is represented as a defined level, within which the company develops its own standard for processes through their documentation, standardization and integration (Wei et al., 2019). In connection with marketing activities, we can describe this level by the fact that the company records all steps taken to determine consumer shopping behavior, then detects its own standard and finally integrates into this standard elements that have proven crucial in examining consumer behavior. A company can also create a set of companywide standards that would serve as a manual for providing advice on individual projects. In this case, the company identifies and understands the shortcomings that need to be addressed and set a goal for improvement.

The fourth level of the CMMI model is the level managed and within it the company monitors and controls its own processes based on careful data collection and analysis. In this case, quantitative data are used, with the basic aim of identifying predictable processes that will be in line with the needs of stakeholders (Ramirez-Mora et al., 2020).

In the case of connection to the marketing of the company, it is necessary to carefully collect all the identified information about consumers, as well as to compile analyzes, the output of which is quantitative data and their evaluation. Subsequently, the company specifies the processes that will be implemented in the future and at the same time will respect the needs of consumers, which were revealed in the case of surveys and subsequent analyzes and their outputs. The last, fifth level, is characterized by optimization, which presupposes the stability and flexibility of business processes. When a company reaches its final stage, a phase of continuous improvement and the ability to adapt to changes occurs (Paton-Romero et al., 2019). At this stage, the company is so advanced that it can not only respond to the changes that occur, but is also able to take advantage of the opportunities that are offered to it and is more able to innovate and move forward, taking into account the foreseeable environment. In connection with the marketing area, the company is able to actively respond to the identified changes in customer requirements, in the market environment and can also respond flexibly to opportunities identified in surveys, or can bridge the gap identified in the market and turn it into a strength.

\section{Research results}

Consumer shopping behavior can currently be influenced by many trends that can provoke irrational shopping behavior. In connection with the principles of irrational behavior, it is necessary to point out the use of emotions in advertising space and identify their impact on the customer's shopping behavior. In their research, Kranzbühler et al. (2020) argue that emotions are evaluation patterns that influence consumer behavior. The authors emphasized that emotions are important in influencing shopping behavior. However, they can generate positive reactions in consumers in the form of humor, joy or surprise associated with humor. In addition to the positive ones, emotional appeals causing negative reactions in consumers also come to the fore. A generalized premise of the research by Rathore and Ilavarasan (2020) is to point out the current trend in the form of evoking negative emotions in advertising space. This means that negative emotions in advertising space can evoke in consumers a feeling of sadness, disgust, the creation of nostalgic memories associated with a certain life event, or a feeling of anger or fear of a certain reaction or event. If a negative emotional appeal is badly applied in the advertising space, it can affect the fulfillment of the company's marketing strategy. However, the company may intentionally create an advertising message with a negative emotional appeal. In this case, it is important to use this emotion correctly with respect to the product or service being promoted.

An effectively implemented communication policy should appropriately create affective responses that can strengthen the customer-brand relationship. It is this relationship that is a response to the current trend of using emotions in the marketing space. In such a case, it is a qualitative factor that the company must take into account in relation to change management and correctly apply to the overall marketing strategy of the company.

\subsection{Methodology of research}

As we have stated in previous chapters, the aim of our research is to point out the current state of consumer 
shopping behavior. As part of the current situation, we identify factors that may support the irrationality of shopping behavior. In the survey, we also identified a possible correlation between selected descriptive variables.

The statistical set consists of Slovak consumers aged 18 and over. The statistical unit is one Slovak consumer who is more than 18 years old and is aware of his shopping behavior. The statistical element is purchasing behavior, in which statistical units satisfy their needs and the needs of their surroundings. In order to obtain valuable data, we used a non-standardized questionnaire method. We distributed the questionnaire in electronic form using the online platform Google Forms. We carried out the survey in the period from 01.07.2020-03.02.2021.

Since the statistical set can be every inhabitant of the Slovak Republic over 18 years of age, we determined the relevant size of the statistical sample according to a mathematical formula. According to demographic and social statistics of the population balance by age, 4,047,779 inhabitants live in the Slovak Republic over the age of 18 as of 21.05.2020.

From the total population, we calculated the relevant size of the statistical sample of respondents according to the mathematical relationship below. We have defined 4 key variables in the formula, which are the size of the sample, the $\mathrm{Z}$ value from the statistical tables, the share of the character for unknown values and the permissible margin of errors. We determined the relevant size of the statistical sample according to the following mathematical relation:

$$
n=\frac{Z^{2} \times p \times(1-p)}{c^{2}}
$$

where: $Z$ - value from statistical tables, $p$ - character share, $c$ - permissible margin of errors, $n$ - sample size.

We set the confidence level at $95 \%$, which corresponds to a $Z$ value of 1.96 . We set the proportion of the character at unknown values to 0.5 . We allow a deviation of $5 \%$. We determined the result as follows:

$$
\begin{aligned}
& n=\frac{1.96^{2} \times 0.5 \times(1-0.5)}{0.05^{2}} ; \\
& n=384 .
\end{aligned}
$$

According to the result, the relevant size of the statistical sample is 384 respondents. The expected return of non-standardized questionnaires within the research was 450 . Of the total expected number, 412 respondents completed the questionnaire, but we excluded 5 questionnaires due to different nationality - the Czech Republic and Ukraine. Due to the exclusion of 5 questionnaires, the return rate was $90.44 \%$ with all completed questions and the number of respondents who participated in the survey was 407 .

According to the result, the relevant size of the statistical sample is 384 respondents. The expected return of non-standardized questionnaires within the research was 450 . Of the total expected number, 412 respondents completed the questionnaire, but we excluded 5 questionnaires due to different nationality - the Czech Republic and Ukraine. Due to the exclusion of 5 questionnaires, the return rate was $90.44 \%$ with all completed questions and the number of respondents who participated in the survey was 407 .

\subsection{Methodology of research}

Verifying dependencies between categorical variables is key to identifying factors that influence customers' shopping behavior. Based on this finding, we can identify changes in the process steps of creating the overall marketing strategy of the company.

The methodology for verifying categorical variables consisted of defining a null and then an alternative hypothesis, determining the level of significance, calculating test statistics and defining the $\mathrm{P}$ value of the test, and deciding whether to accept or reject hypothesis $\mathrm{H} 0$.

We used the SPSS Statistics test program to evaluate the dependencies between the categorical variables. The chosen test statistic among the variables examined was the Pearson Chi-Sqaure test. If a dependence was found, we measured its strength with Cramer's V test statistics.

Hypothesis 1:

In the questionnaire survey, we asked the respondents how strongly their advertising behavior is influenced by advertising with an emotional appeal. We showed the result of descriptive statistics in the following contingency

\begin{tabular}{|c|c|c|c|c|c|c|c|}
\hline \multirow{8}{*}{$\begin{array}{l}\text { Gross } \\
\text { monthly } \\
\text { income }\end{array}$} & \multicolumn{6}{|c|}{ How strongly does advertising with an emotional appeal affect you? } & \multirow[b]{2}{*}{ ALONGS } \\
\hline & & $\begin{array}{l}\text { It doesn't } \\
\text { always work }\end{array}$ & $\begin{array}{l}\text { Sometimes it } \\
\text { doesn't work }\end{array}$ & $\begin{array}{l}\text { It doesn't } \\
\text { work or it } \\
\text { works }\end{array}$ & $\begin{array}{l}\text { Sometimes it } \\
\text { works }\end{array}$ & $\begin{array}{l}\text { It always } \\
\text { works }\end{array}$ & \\
\hline & $\leq 622 €$ & 37 & 51 & 57 & 26 & 15 & 186 \\
\hline & $623 €-738 €$ & 5 & 14 & 27 & 6 & 3 & 55 \\
\hline & $739 €-854 €$ & 21 & 10 & 19 & 3 & 3 & 56 \\
\hline & $855 €-970 €$ & 32 & 24 & 22 & 6 & 5 & 89 \\
\hline & $971 €-1086 €$ & 9 & 9 & 1 & 0 & 2 & 21 \\
\hline & ALONGS & 104 & 108 & 126 & 41 & 28 & 407 \\
\hline
\end{tabular}
Table 1.

Table 1. Frequencies of advertising with an emotional appeal to respondents according to gross monthly income 
According to the individual numbers, we can see that advertising with an emotional appeal has the strongest effect on respondents with an income equal to or less than $€$ 622. However, we can see the intense effect of advertising with an emotional appeal to respondents whose monthly income is in the range of $€ 623-€ 738$.

In order to determine the significant influence of factors, we decided to establish Hypothesis no. 1. This is a presumption of the dependence between the categorical variables gross monthly income and the scope of advertising with an emotional appeal to customers' shopping behavior.

As already mentioned, to verify the dependence between the categorical variables, we used the Pearson ChiSquare test, the $\mathrm{p}$ value of which we compared with the selected level of significance $\alpha=0.05$. The test results are shown in Table 2.

Table 2. The result of the verification of Hypothesis no. 1 by Pearson's Chi-Square test

\begin{tabular}{|l|c|c|c|}
\hline & Value & df & $\begin{array}{c}\text { Asymptotic } \\
\text { Significance (2-sided) }\end{array}$ \\
\hline Pearson Chi-Square & $37.312^{\mathrm{a}}$ & 16 & $\mathbf{0 . 0 0 2}$ \\
\hline Likelihood Ratio & 42.434 & 16 & 0.000 \\
\hline $\begin{array}{l}\text { Linear-by-Linear } \\
\text { Association }\end{array}$ & 11.052 & 1 & 0.001 \\
\hline N of Valid Cases & 407 & & \\
\hline
\end{tabular}

The $\mathrm{P}$ value of the test is at the level of 0.002 ; which is at the selected level of significance $\alpha=0.05$ less. In the case of Hypothesis no. 1 is an inequality, ie we reject the hypothesis $\mathrm{H} 0$ at the level of significance $\alpha=0.05$ and we claim that there is a dependence between the categorical variables gross monthly income and the scope of advertising with an emotional appeal to customers' shopping behavior.

Due to the existence of dependence, we decided to measure its strength, for which we used the Cramer's V test. The results of testing the strength of dependence between categorical variables are shown in Table 3.

From Table 3 shows the value of Cramer's V 0.149; which represents a weak contingency between categorical variables. By comparing the $\mathrm{p}$ value (0.002) of Cramer's test with a significance level of $\alpha=0.05$; we can accept an alternative hypothesis about the statistical significance of the contingency coefficient.
Table 3. The result of the verification of the strength of the dependence of Hypothesis no. 1 by Cramer's V

\begin{tabular}{|l|c|c|c|}
\hline & & Value & $\begin{array}{c}\text { Approximate } \\
\text { Significance }\end{array}$ \\
\hline $\begin{array}{l}\text { Nominal by } \\
\text { Nominal }\end{array}$ & Phi & 0.289 & 0.002 \\
\hline & Cramer's V & $\mathbf{0 . 1 4 9}$ & $\mathbf{0 . 0 0 2}$ \\
\hline N of Valid Cases & & 407 & \\
\hline
\end{tabular}

Hypothesis 2:

In addition to the influence of advertising with an emotional appeal on the shopping behavior of respondents, we found out in the questionnaire the influence of the factor on irrational shopping behavior. The question focused on the selection of one of two different sweet products that were of the same nature (e.g. candy wrappers). The products had a differentiated price level, but we did not identify them in the question in order to maintain the generality of the phenomenon under investigation. The first product was sold for $€ 3.20$ and the second was sold for $€ 4.20$ with the option to get a free package of playing cards to buy the product. In the question, we investigated the possible impact of the gift as an irrational factor on the final purchase decision. The answers are shown in Figure 4.

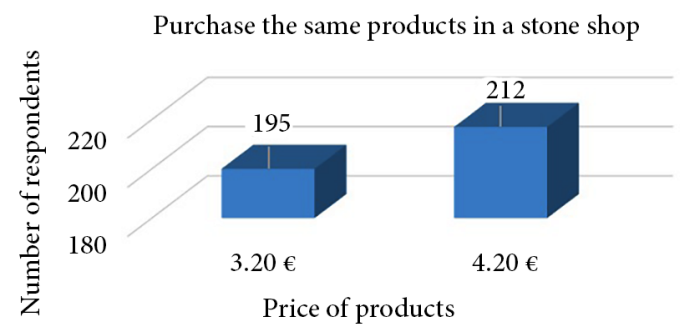

Figure 4. Respondents' answers in relation to a question aimed at purchasing the same products

Initial results suggest that respondents preferred a product of the same nature, which was $€ 1$ more expensive with the option to obtain a free deck of playing cards. From the above, we can say that the respondents were subject to an irrational factor. They did not take into account the price of the products, despite the fact that they were products of the same nature with the same brand. Out of the total number of 407 respondents, 212 would be chosen for the second product, which represents a share of $52.08 \%$. The remaining 195 respondents would choose the

Table 4. Frequency of decision - making between two products in relation to the gross monthly wage of the respondents

\begin{tabular}{|c|c|c|c|c|c|c|c|}
\hline \multirow{5}{*}{$\begin{array}{l}\text { Deciding } \\
\text { between } \\
\text { two } \\
\text { products }\end{array}$} & \multicolumn{6}{|c|}{ Gross monthly income } & \multirow{2}{*}{ ALONGS } \\
\hline & & $\leq 622 €$ & $623 €-738 €$ & $739 €-854 €$ & $855 €-970 €$ & $971 €-1086 €$ & \\
\hline & Product for $€ 3.20$ & 80 & 27 & 28 & 48 & 12 & 195 \\
\hline & Product for $€ 4.20+$ free deck of cards & 111 & 28 & 27 & 39 & 7 & 212 \\
\hline & ALONGS & 191 & 55 & 55 & 87 & 19 & 407 \\
\hline
\end{tabular}


first product. In order to find out which socio-economic group marked the second answer the most, we created a contingency Table 4.

The paradox is the answers of respondents whose gross monthly income is less than or equal to $€ 622$. Despite the low income, these respondents would have decided more to buy a second product with the option of obtaining a deck of playing cards for free. We can thus say that these respondents did not think rationally when choosing products. Respondents' rational thinking can be seen in those whose gross monthly salary is $€ 739$ and more.

In order to determine the significant influence of factors, we decided to establish Hypothesis no. 2. This is the assumption of the dependence between the categorical variables gross monthly income and the decision between two sweet products. We used the Pearson Chi-Square test statistic to verify the dependence. The results of the test statistics are shown in the following Table 5.

Table 5. Verification of dependencies in Hypothesis no. 2

\begin{tabular}{|l|c|c|c|l|}
\hline Factors & $\begin{array}{c}\text { Pearson's } \\
\text { Chi-Square } \\
\text { (p-value) }\end{array}$ & $\begin{array}{c}\text { Hypo- } \\
\text { thesis }\end{array}$ & $\begin{array}{c}\text { Cramer's V } \\
\text { (p-value) }\end{array}$ & Test result \\
\hline $\begin{array}{l}\text { Hypo- } \\
\text { thesis 2 }\end{array}$ & 0.045 & $\begin{array}{c}\mathrm{H}_{0} \\
\mathrm{p}<0.05\end{array}$ & 0.045 & $\begin{array}{l}\text { Rejection } \\
\mathrm{H}_{0} \text { : there a } \\
\text { dependency }\end{array}$ \\
\hline
\end{tabular}

We compared the determined $\mathrm{p}$-value with the significance level $\alpha=0.05$. Since the $\mathrm{p}$-value is less than the significance level, we decided to reject the null hypothesis of no dependence between categorical variables and to accept the alternative hypothesis $\mathrm{H} 1$ of the existence of dependence between the variables gross monthly income and the decision between two sweet products.

Due to the existence of dependencies between categorical variables, we also tested its strength. The value of Cramer's V is 0,164; which represents a weak contingency between the examined variables. We can thus say that there is a weak dependence between the variables. The P-value of Cramer's in the test is 0.045; which is less compared to the significance level $\alpha=0.05$. This means that we accept an alternative hypothesis about the statistical significance of the Cramer's V contingency coefficient.

\section{Discussion}

The dependence in relation to the scope of advertising with an emotional appeal, we confirmed Hypothesis no. 1. In it, we considered gross monthly income as the primary factor. By confirming the dependence, we can express that advertising with an emotional appeal has a different effect on respondents with different categories of gross monthly income. From the results of the defined frequencies in Table 1, we can confirm that the largest percentage in this income category are respondents aged 18 to 25 years. We can thus confirm that this age category belongs to the group of adolescents. The impact of the emotional impact of advertising on adolescents is crucial in influencing shopping behavior. The research by Barve et al. (2015) show that adolescents intensely perceive the influences and effects of ads with emotional appeal, which can also affect their resulting behavior in a market environment. The authors' research problem was to analyze the negative and positive effects of television advertising on adolescents. Using questionnaire methods and structured interviews, the authors found more emotional reactions in girls and higher rationality in boys. As a result, adolescents' adherence of gender-based stereotypes, aggressive behavior, and social apathy developed. Similar to Barve et al. (2015), Sinigh and Pandey (2017) analyzed the impact of emotional appeals on adolescents. The results of their research were identified with the statements of the authors Barve et al. (2015) on the impact of emotional television advertising campaigns on the female segment. Research has shown that adolescents are exposed to 400,000 types of ads with a differentiated emotional appeal each year. Evidence of the influence of emotions in advertising space is also the claim of the authors Ho et al. (2006) that the use of emotions in advertising space can lead to higher interaction between the customer and the company. The authors have generalized this statement and therefore their view is acceptable in companies operating in different market sectors.

In the second hypothesis, we examined a selected factor that can support irrationality in shopping behavior.

We found a relationship between gross monthly income and decisions between two sweet products. Among the examined variables, we also confirmed the existence of dependence. We can argue that the gross monthly income of respondents has a different effect on purchasing decisions between two sweet products with different price levels. In Table 4 we pointed out the fact that respondents whose gross monthly income is less than or equal to $€$ 622 would rather decide to buy a second product with the possibility of obtaining a gift. However, according to our research, we can include respondents aged 18 to 25 in this category. Therefore, in this context, it is necessary to focus on the influence of factors and emotional appeals on adolescents, for whom we also noticed significant effects of a factor that supported their irrational shopping behavior. Research by Dhaliwal et al. (2020) pointed to a link between emotions, irrational behavior and price. Although the authors in their research focused on luxury products, their results can generally be applied to different categories of products. The authors of their research found that a product that is promoted with a certain emotion can provoke irrational behavior in the customer until the moment the customer encounters the price of the product. In this sense, there is a need for another incentive on the part of the seller, which can strengthen irrationality in purchasing behavior. The company can thus use various sales support tools in order to make a positive final decision of the customer (Dhaliwal et al., 2020). In their research, the authors pointed out the importance of the influence of 
emotions and other factors that can support the irrationality of shopping behavior. On the one hand, we agree with the authors' statement, but it is also necessary to focus on internal marketing processes. There should be changes in them, by which the company will effectively support positive purchasing decisions for customers.

In this context, the creation of a marketing strategy is gaining attention. In terms of its creation, we would generally recommend the company to rely on the third level of the CMMI process model, which is an element of change management. We consider it necessary for a company in the field of change management to be able to achieve at least the third level of the CMMI model, as a starting phase for initiating changes and linking change management with the marketing department. The first step is to carry out a market survey specifying many factors that the company has identified as important from a subjective point of view, taking into account its own portfolio of products offered. The aim is to find out which factors consumers perceive as decisive when it comes to their purchasing decisions. It is also important to focus on those factors that are responsible for influencing the customer's emotions during his purchase decision, given our finding that emotional factors are also crucial in the area of customer shopping behavior. Subsequently, on the basis of the findings obtained through the analysis of its findings, the company has to extract the most important factors, which have been identified as the most important from the customer's point of view. These factors will need to be included in the design of the marketing strategy. On the basis of the above, the company then documents all the findings concerning consumer behavior. It then identifies critical areas for findings and can design an enterprise standard that is the starting point for achieving the third level of the CMMI model. At the same time, the creation of a corporate standard, which contains elements to improve business processes, becomes an input element for change management, and at this moment there is an interaction between change management and the field of marketing. After the adoption of the corporate standard, the change management department then prepares all the necessary documents for the implementation of marketing changes and submits them to the marketing department. The overall output of our proposed model is the introduction of a new concept of change marketing, which is a subset of change management. The model we designed is shown in Figure 5 using the process steps.

We evaluate the connection of change management with the marketing area through process management as beneficial, mainly for the following reasons. The entry of process management, which is part of change management, can bring several positive elements to the marketing area. Through a process approach to corporate change, which is implemented as a sequence of individual steps, it is possible to approach the considered changes comprehensively. They will also effectively intervene in the marketing area and the creation of a communication campaign, which should be an essential part of the company's

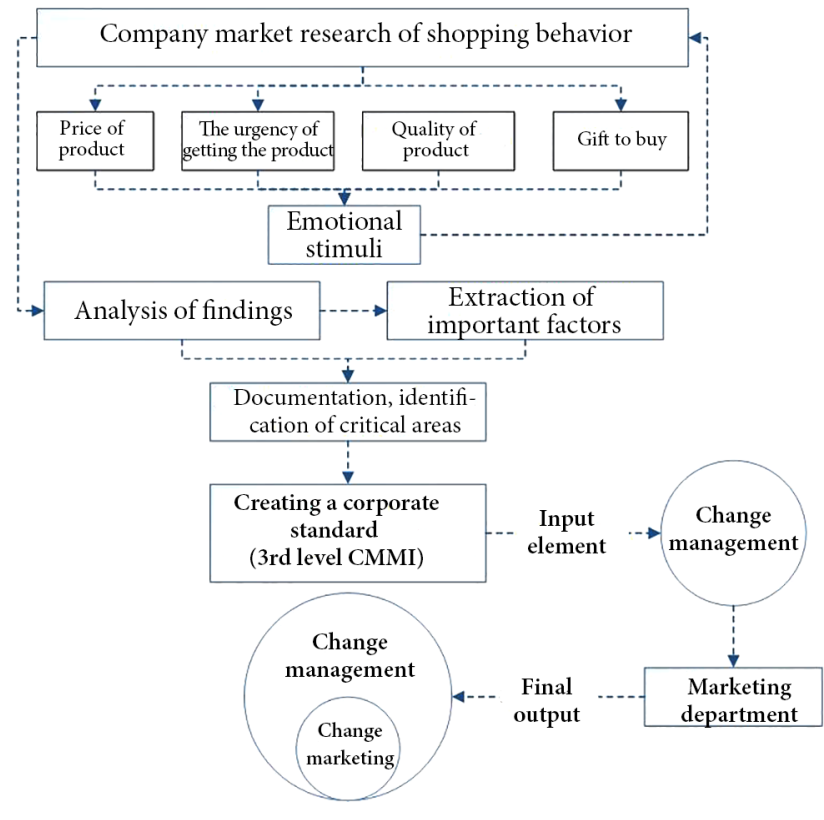

Figure 5. Behavioral model of change management with emphasis on marketing

overall marketing strategy. Another advantage is that through the process of change, the creation of value for the customer is determined, which in the future may affect his final purchasing decision. This aspect is very important for the company, as the goal of every company is to build competitiveness, loyalty and strengthen the brand. Business decisions in the preparation of a specific change process are always subordinated to the needs of the customer, which are the guiding feature for determining the goal and setting the steps of the change process.

Research has shown that the current market environment in which companies operate is marked by dynamic developments that determine the need to implement and manage business change. Business changes must be implemented with regard to the field of marketing, because marketing as a corporate department directly affects the behavioral aspects of customer approaches to the product portfolio of each company. For this reason, the concept of marketing activities is conditioned by changes that the company implement and manage due to the company's vision and achieving favorable results.

The authors who dealt with the issue of CMMI models agree that the representation of model elements in business processes makes it possible to identify elements that are an important part of the business processes themselves. Thanks to their representation in business processes, there is a significant facilitation of understanding the process and guiding their application Zapata et al. (2015). We also agree with this statement, emphasizing the importance of mutual coordination between the creation of marketing strategy and the third level of the CMMI model as a conditional level for the creation of marketing strategy to generate successful effects for the company. The CMMI model is one of the elements of an independent business discipline - change management, and we consider 
the importance of change management to be striking in relation to marketing as a separate business area and its activities.

\section{Conclusions}

Through the conducted research, we contributed to the knowledge of the scientific department of change management. We connected internal marketing processes in creating a communication campaign with external factors influencing the behavioral characteristics of customers' shopping behavior. In the introductory part of the article, we identified the subject of our research, including the hypotheses that we verified in the third chapter. In the discussion part of the article, we effectively linked the importance of changing internal processes in relation to the external environment.

By analyzing the theoretical basis of domestic and foreign authors and practical research, we have contributed to the development of change management as an independent scientific discipline. In this context, we have come to the conclusion that linking the analysis of customers' shopping behavior with internal business processes requires bringing a new concept of marketing change to the forefront. This can be understood as a separate subset of the change management process. The discussion part of the article provides a basis for further research and development of the concept of marketing changes and in the conditions of shopping behavior of Slovak consumers.

\section{Acknowledgements}

This paper is an output of scientific project VEGA no. $1 / 0032 / 21$ : Marketing engineering as a progressive platform for optimizing managerial decision-making processes in the context of the current challenges of marketing management.

\section{References}

Adekiya, A. A. (2016). Change, customer satisfaction and competition: Issues from the strategic management context. International Journal of Economics, Business and Management Studies, 3(2), 55-66.

Barve, G., Sood, A., Nithya S., \& Virmani, T. (2015). Effects of advertising on youth (age group of 13-19 years age). Journal of Mass Communication \& Journalism, 5(5), 3-9. https://doi.org/10.18535/ijmei/v1i10.02

Baumeister, R. F., Kathleen, D. V., \& Dianne, M. T. (2012). Emotional influences on decision making. Taylor and Francis.

Beall, T. A., \& Tracy, L. J. (2017). Emotivational psychology: How distinct emotions facilitate fundamental motives. Social and Personality Psychology Compass, 11(2), 350-367. https://doi.org/10.1111/spc3.12303

Berne-Manero, C., \& Marzo-Navarro, M. (2020). Exploring how influencer and relationship marketing serve corporate sustainability. Sustainability, 12(11), 1-19.

https://doi.org/10.3390/su12114392
Chen, Y. M., \& Yang, Z. L. (2020). The behavioral analysis of choice difficulty states during clothing online shopping. International Journal of Clothing Science and Technology, 33(4), 577-589. https://doi.org/10.1108/IJCST-12-2019-0189

Chen, Y. S., Chen, J. T., \& Lin, Ch. (2016). The analyses of purchasing decisions and brand loyalty for smartphone consumers. Open Journal of Social Sciences, 4(7), 108-116. https://doi.org/10.4236/jss.2016.47018

Clore, G. L. (2011). Psychology and the rationality of emotion. Modern Technology, 27(2), 209-222. https://doi.org/10.1111/j.1468-0025.2010.01679.x

Clore, G. L., \& Huntsinger, J. R. (2007). How emotions inform judgment and regulate thought. Trends in Cognitive Sciences, 11(9), 393-399. https://doi.org/10.1016/j.tics.2007.08.005

Deng, J. Q., Zhang, N., Ahmad, F., \& Draz, M. U. (2019). Local government competition, environmental regulation intensity and regional innovation performance: An empirical investigation of Chinese provinces. International Journal of Environmental Research and Public Health, 16(12), 2130.

https://doi.org/10.3390/ijerph16122130

Dhaliwal, A., Singh, P. D., \& Paul, J. (2020). The consumer behavior of luxury goods: A review and research agenda. Journal of Strategic Marketing, 29(6), 1-27. https://doi.org/10.1080/0965254X.2020.1758198

Gubruz, I. B. \& Macabangin, M. (2019). Factors affecting consumer's behaviour on purchasing and consumption of food products. Scientific Papers Series Management, Economic Engineering in Agriculture and Rural Development, 19(1), 215-222.

Ho, T., H., Lim, N., \& Camerer, C. F. (2006). Modeling the psychology of consumer and firm behavior with behavioral economics. Journal of Marketing Research, 43(3), 307-331. https://doi.org/10.1509/jmkr.43.3.307

Jermsittiparsert, K., Siam, M. R. A., Issa, M. R., Ahmed, U., \& Pahi, M. H. (2019). Do consumers expect companies to be socially responsible? The impact of corporate social responsibility on buying behavior. Uncertain Supply Chain Management, 7(4), 741-752. https://doi.org/10.5267/j.uscm.2019.1.005

Kranzbühler, A. M., Zerres, A., Kleijnen, M., \& Verlegh, P. W. J. (2020). Beyond valence: A meta-analysis of discrete emotions in firm-customer encounters. Journal of the Academy of Marketing Science, 48(3), 478-498.

https://doi.org/10.1007/s11747-019-00707-0

Littlechild, S. (2019). Promoting competition and protecting customers? Regulation of the GB retail energy market 20082016. Journal of Regulatory Economics, 55(2), 107-139. https://doi.org/10.1007/s11149-019-09381-0

Paton-Romero, J. D., Baldassarre, M. T., Rodriguez, M., \& Piattini, M. (2019). Maturity model based on CMMI for governance and management of Green IT. IET Software, 13(6), 555-563. https://doi.org/10.1049/iet-sen.2018.5351

Plessis, E. (2011). How the customer perceives the brand. Computer Press.

Pour, M. J., \& Jafari, S. M. (2019). Toward a maturity model for the application of social media in healthcare: The health 2.0 roadmap. Online Information Review, 43(3), 404-425. https://doi.org/10.1108/OIR-02-2018-0038

Ramirez-Mora, S. L., Oktaba, H., \& Perez, J. P. (2020). Group maturity, team efficiency, and team effectiveness in software development: A case study in a CMMI-DEV Level 5 organization. Journal of Software-Evolution and Process, 32(4), 2232. https://doi.org/10.1002/smr.2232

Rathore, A. K., \& Ilavarasan, P. V. (2020). Pre-and post-launch emotions in new product development: Insights from Twitter 
analytics of three products. International Journal of Information Management, 50, 111-127.

https://doi.org/10.1016/j.ijinfomgt.2019.05.015

Sinigh, M., \& Pandey, A. (2017). Effects of emotional appeal used in television ads on purchase decision of consumer a literature review. International Education \& Research Journal, 3(5), 176-178.

Sjodin, D. (2019). Knowledge processing and ecosystem cocreation for process innovation: Managing joint knowledge processing in process innovation projects. International Entrepreneurship and Management Journal, 15(1), 135-162. https://doi.org/10.1007/s11365-018-0550-3

Socha, T. J., \& Beck, A. G. (2015). Positive communication and human needs: A review and proposed organizing conceptual framework. Review of Communication, 15(3), 173-199. https://doi.org/10.1080/15358593.2015.1080290

Srivastava, R. K., \& Wagh, S. (2017). Factors impacting consumer purchase behaviour for pharmaceutical products. International Journal of Healthcare Management, 13(2), 113-121. https://doi.org/10.1080/20479700.2017.1348004
Victor, V., Thoppan, J. J., Jeyakumar Nathan, R., Farkas Maria, F. (2018). Factors influencing consumer behavior and prospective purchase decisions in a dynamic pricing environment an exploratory factor analysis approach. Social Sciences, 7(9), 153. https://doi.org/10.3390/socsci7090153

Vuorinen, L., \& Martinsuo, M. M. (2019). Lifecycle view of managing different changes in projects. International Journal of Managing Projects in Business, 12(1), 120-143. https://doi.org/10.1108/IJMPB-11-2017-0135

Wei, J., Chen, H., Long, R. Y., \& Zhao, F. (2019). Application of the capability maturity model to evaluating the carbon capability maturity of urban residents in 10 Eastern provinces of China. Resources Conservation And Recycling, 148, 11-22. https://doi.org/10.1016/j.resconrec.2019.04.029

Zapata Jaramillo, C. M., Valderrama Betancur, J., \& Jimenez Pinzon, L. D. (2015). Representation of CMMI-DEV practices in the Semat kernel. IEEE Latin America Transactions, 13(10), 3476-3481.

https://doi.org/10.1109/TLA.2015.7387257 